\title{
A quantitative comparison of towed-camera and diver-camera transects for monitoring coral reefs
}

\author{
Anna K Cresswell ${ }^{\text {Corresp., }, ~}{ }^{2}$, Nicole M Ryan ${ }^{1}$, Andrew J Heyward ${ }^{1}$, Adam N H Smith ${ }^{3}$, Jamie Colquhoun ${ }^{1}$, Mark Case \\ , Matthew J Birt ${ }^{1}$, Mark Chinkin ${ }^{1}$, Mathew Wyatt ${ }^{1}$, Ben Radford ${ }^{1,2}$, Paul Costello ${ }^{4}$, James P Gilmour ${ }^{1,2}$ \\ ${ }^{1}$ Australian Institute of Marine Science, Perth, Western Australia, Australia \\ 2 Oceans Institute, University of Western Australia, Perth, Western Australia, Australia \\ 3 School of Natural and Mathematical Sciences, Massey University, Auckland, New Zealand \\ 4 Australian Institute of Marine Science, Townsville, Queensland, Australia \\ Corresponding Author: Anna K Cresswell \\ Email address: a.cresswell@aims.gov.au
}

Novel tools and methods for monitoring marine environments can improve efficiency but must not compromise long-term data records. Quantitative comparisons between new and existing methods are therefore required to assess their compatibility for monitoring. Monitoring shallow water coral reefs typically uses diver-based collection of benthic images along transects. Diverless systems for obtaining underwater images (e.g. towedcameras, remotely operated vehicles, autonomous underwater vehicles) are increasingly used for mapping coral reefs. Of these imaging platforms, towed-cameras offer a practical, low cost and efficient method for surveys over wider areas and depths, but their utility for repeated measures in monitoring studies has not been tested. We quantitatively compare a towed-camera approach to repeated surveys of shallow water coral reef benthic assemblages on fixed transects, relative to benchmark data from diver photo-transects. Differences in the percent cover detected by the two methods was partly explained by differences in the morphology of benthic groups. The reef habitat and physical descriptors of the site - slope, depth, and structural complexity - also influenced the comparability of data, with differences between the tow-camera and the diver images increasing with structural complexity and slope. Differences between the methods also decreased when a greater number of images were collected per tow-camera transect. We attribute lower image quality (variable perspective, exposure and focal distance) and lower spatial accuracy and precision of the towed-camera transects as the key reasons for differences in the data from the two methods and suggest changes to the sampling design to improve the application of the tow-camera to monitoring. 


\section{A quantitative comparison of towed-camera and diver- 2 camera transects for monitoring coral reefs}

3

4

5

6

7

8

9
Anna K. Cresswell ${ }^{1,2}$, Nicole M. Ryan ${ }^{1}$, Andrew J. Heyward ${ }^{1}$, Adam N. H. Smith ${ }^{3}$, Jamie Colquhoun $^{1}$, Mark Case ${ }^{1}$, Matthew J. Birt ${ }^{1}$, Mark Chinkin ${ }^{1}$, Mathew Wyatt ${ }^{1}$, Ben Radford ${ }^{1,2}$, Paul Costello ${ }^{4}$, James P. Gilmour ${ }^{1,2}$

${ }^{1}$ Australian Institute of Marine Science, Perth, Western Australia, Australia ${ }^{2}$ Oceans Institute, University of Western Australia, Perth, Western Australia, Australia ${ }^{3}$ School of Natural and Mathematical Sciences, Massey University, Auckland, New Zealand ${ }^{4}$ Australian Institute of Marine Science, Townsville, Queensland, Australia

Corresponding Author:

Anna Cresswell ${ }^{1,2}$

Australian Institute of Marine Science, 36 Fairway, Crawley, WA, Australia

Email address: annacresswell@gmail.com 


\section{Abstract}

22

23

24

25

26

27

\section{2}

53

Novel tools and methods for monitoring marine environments can improve efficiency but can introduce unwanted variability into long-term data records. Quantitative comparisons between new and existing methods are critical to assess their compatibility for monitoring. Monitoring shallow water coral reefs typically uses diver-based collection of benthic images along transects. Diverless systems for obtaining underwater images (e.g. towed-cameras, remotely operated vehicles, autonomous underwater vehicles) are increasingly used for mapping coral reefs. Of these imaging platforms, small towed-cameras offer a potentially practical, low cost and efficient method for monitoring reef areas of similar scale and taxonomic resolution to diver phototransects, but this has not been tested quantitatively. We compare percent cover data of sessile benthic organisms obtained from a small towed-camera with those obtained from diver fixed position photo-transects. The tow-camera images yielded a mean cover of $12.6 \%$ that could not be identified into the benthic or coral groups, whereas the diver had only $1.3 \%$. Further variation in the percent cover of benthic groups detected by the two methods was partly explained by differences in the morphology of the groups. The nature of the reef habitat and physical descriptors of the site - slope, depth, and substratum complexity — also influenced the comparability of data, with differences between the tow-camera and the diver data increasing with substratum complexity and slope. Data were more comparable when a greater number of images were collected per tow-camera transect. We attribute lower spatial accuracy and precision of the towed-camera transects, together with lower image quality and consistency (more variable perspective, exposure and focal distance), as the key reasons that the tow-camera did not reproduce the diver data. If tow-cameras are to be used for monitoring shallow coral reefs sampling designs should therefore be tailored to the strengths of tow-cameras (quickly acquire large numbers of images) and weaknesses (lower spatial accuracy and precision than fixed diver surveys). Given some differences in the data from the two methods we advise any established long-term monitoring programs should maintain continuity in methods, but if not, direct comparison studies like the one presented here are needed to provide a quantitative assessment of the sources of variation between methods.

\section{Introduction}

Marine mapping and monitoring programs need accurate and precise assessments of benthic communities. An increased focus on monitoring coral reefs followed the first global coral bleaching event in 1998, given the unprecedented scale and severity of impacts (Houk \& Van Woesik 2013). Coral reefs have since been the subject of some of the most extensive monitoring in the marine environment (Mellin et al. 2020). Many coral reef monitoring programs involve recording the percent cover of corals and other benthic groups from photographs obtained by scuba divers, usually collected along a transect line, i.e. 'photo-transects' (Littler et al. 1997). 
61 The photos are then processed by placing random or fixed points on the images, identifying the

62 benthic organism under the points, and converting this to an estimate of percent cover (Jonker et

63 al. 2008). Comparisons of marine benthic communities among locations and through time

64 depend on consistency in survey design, scale, replication and methods (Brown et al. 2004;

65 Edmunds 2013; Galzin et al. 2016; Jonker et al. 2008; Obura et al. 2017).

66

67

68

69

70

71

72

73

74

75

76

77

78

79

80

81

82

83

84

85

86

87

88

89

90

91

92

93

94

95

96

97

98

99
Monitoring programs usually require expensive and time-consuming field work, particularly at reefs that are remote or difficult to access, making it important to allocate survey effort effectively (McDonald-Madden et al. 2010). Advances in technology offer opportunities for collection of image-based data via novel methods that may be safer, more efficient or economical, enable surveys over larger areas, or allow for increased replication and greater statistical power (Houk \& Van Woesik 2006; McDonald-Madden et al. 2010). Furthermore, as acute disturbances to coral reefs increase in spatial scale and frequency (Hughes et al. 2018), rapid, responsive monitoring is important. However, changes in methods increase variability in data and can compromise long-term data series (Bicknell et al. 2016; Durden et al. 2016). Thus, there is ongoing discussion regarding the best methods for coral reef monitoring (Brown et al. 2004; Houk \& Van Woesik 2013; Lam et al. 2006; Leujak \& Ormond 2007; Mellin et al. 2020).

Visual imaging, using photos or video, is an essential component of most marine monitoring methods as it is non-destructive, provides a permanent record and is relatively efficient in the field (Carleton \& Done 1995; Durden et al. 2016; Flannery \& Przeslawski 2015). Imagecollection platforms such as remotely operated vehicles (Raoult et al. 2020), automated underwater video (Foster et al. 2014; Ludvigsen \& Sørensen 2016) and towed-cameras (Carroll et al. 2020; Davis et al. 2019; Sheehan et al. 2016) using digital stills or video continue to become more sophisticated and economical. Among these remote systems, towed-cameras are a practical and efficient method for mapping reefs (Barker et al. 1999; Carleton \& Done 1995; Carroll et al. 2020; Cruz-Marrero et al. 2019; Davis et al. 2019; Lembke et al. 2017) but diverbased collection of images along transects remain the standard for monitoring reefs, with demonstrated ability to capture changes through time at fine spatial scale.

As demonstrated by the evolution from in situ visual census to image-capture in marine monitoring in the mid-1990s (Carlton and Done, 1995), new survey methods will inevitably be introduced into coral reef monitoring programs as technology evolves. Choice of method and survey design have important implications for the effectiveness, cost and interpretation of monitoring efforts (Boavida et al. 2016; Houk \& Van Woesik 2013; Jokiel et al. 2015; Mellin et al. 2020). The method employed should reflect the broader aims of the monitoring program while also considering the scale and taxonomic resolution of the information required, the repeatability of a method and environmental conditions. For example, the ability of towedcamera systems to capture informative seabed imagery can be influenced by sea conditions, 
100 water clarity, and the depth and type of terrain being surveyed (Carroll et al. 2020; Durden et al.

101 2016).

102

103 Understanding how the accuracy and precision of data from new methods compares to the

104 historical benchmarks of diver-based transects is a critical step in assessing their suitability

105 (Flannery \& Przeslawski 2015; Lam et al. 2006). There are various comparisons of diver-based

106 methods with other sampling techniques for fishes (Boavida et al. 2016), but relatively few have

107 focused on benthic invertebrates, algae or benthic communities (Boavida et al. 2016; Brown et

108 al. 2004; Foster et al. 2014; Jokiel et al. 2015; Lam et al. 2006; Leonard \& Clark 1993), and there

109 are no quantitative comparisons of towed-camera systems and diver photo-transect methods for

110 monitoring coral reef habitats, despite their increasing application. Here, we compare surveys of

111 shallow $(<12 \mathrm{~m})$ coral reefs using a small tow-camera system with diver-operated camera

112 surveys on fixed transects in four distinct habitats. This study aims to: (1) determine the accuracy

113 and precision of the towed-camera system in following a fixed-position transect; (2) compare the

114 benthic communities and coral assemblages detected by each method; (3) identify any factors -

115 specifically habitat, depth, substratum complexity or reef slope (gradient) — that explain

116 differences between the two methods; (4) describe the utility and evaluate the best approach to

117 using towed-camera systems for monitoring shallow coral reefs.

118

119

120

121

122

Materials \& Methods

123 Study site

124 The Rowley Shoals is a group of three isolated oceanic shelf reefs near the edge of the

125 continental shelf $\sim 260 \mathrm{~km}$ from mainland north-western Australia (Figure 1). The reefs -

126 named Mermaid, Clerke and Imperieuse - are separated from each other by $>25 \mathrm{~km}$ of oceanic

127 water (Wilson 2013).

128

129

Benthic surveys were conducted in March 2018 and October 2019 at ten permanently marked

130 monitoring sites (Figure 1). Sites were stratified by four habitats: 'slope' on the reef slope at $\sim 6$

131 m depth (at lowest astronomical tide, LAT); the 'crest' on the reef crest at $\sim 3 \mathrm{~m} \mathrm{LAT}$, both on

132 the outer eastern boundary of Mermaid, Clerke and Imperieuse reefs; 'lagoon floor' at the base

133 of coral bommies in the lagoon at Clerke and Mermaid reefs (9-12 m LAT); and 'bommie' on

134 the top of coral bommies in the lagoon at Clerke and Mermaid reefs ( $\sim 1 \mathrm{~m}$ LAT) (Figure 1).

135 Surveys were prioritized during slack tides, when winds were below 20 knots and swell was less

136 than $1 \mathrm{~m}$.

137 
138 Permits to conduct these surveys were received from the Australian Government Department of

139 the Environment (Mermaid Reef Commonwealth Reserve), the Western Australian Department

140 of Primary Industries and Regional Development (DPIRD \#2999) and the Western Australian

141 Department of Biodiversity, Conservation and Attractions.

142

\section{Survey methods}

144 At each site there were continuous transects, each separated by approximately $10 \mathrm{~m}$, with fixed

145 markers along each. The total length of transects was $250 \mathrm{~m}$ on the reef slope (composed of five

$14650 \mathrm{~m}$-long transects), $150 \mathrm{~m}$ on the reef crest (three $50 \mathrm{~m}$-long), and 120-150 $\mathrm{m}$ at the lagoon

147 floor and coral bommie sites (three $50 \mathrm{~m}$-long in 2018 and six $20 \mathrm{~m}$-long in 2019) (Figure 2).

148 Reef crest and slope transects ran along depth contours parallel to the reef crest, while the lagoon

149 floor and bommie transects wrapped around the base or top of the bommies respectively (Figure

150 S 1.3, Figure S 1.4).

151

152 Sites were surveyed on scuba following the standard operation procedures (SOP) of the AIMS

153 long-term monitoring program (Jonker et al. 2008). The dive team required 2-3 personnel

154 (photographer and dive buddy, surface attendant if needed). The divers used a digital Canon

155 PowerShot G1 X Mark II (12.8 MP, 1.5 inch sensor) in an underwater housing, photographing

156 the substrate every metre along the transects, with the camera held perpendicular $\sim 50 \mathrm{~cm}$ from

157 the substratum (Figure 2). The resulting images each capture an area of approximately $23 \times 30 \mathrm{~cm}$.

158 It took $\sim 45-60$ minutes to collect images along five $50 \mathrm{~m}$ end-to-end transects, depending on the

159 substratum complexity of the reef and the water conditions, such as surge or current. After the

160 images were collected, a geo-referenced track of the transects was obtained by a swimmer

161 following the transect line at the surface with a GPS.

162

163 The 'tow-camera' was designed to be hand deployable from a tender or small vessel for the

164 specific purpose of surveying shallow reef areas that have traditionally been surveyed by divers.

165 The system is therefore lightweight, battery powered, and much smaller than more traditional

166 tow-video systems (e.g. Carroll et al. 2020), measuring 25x27x75 cm. The tow-camera system

167 consists of an aluminum frame, to which an oblique-angled high-definition Sony analogue video

168 camera is attached, providing a live video feed via a $30 \mathrm{~m}$ loadbearing cable to a monitor

169 (Atmos) on the boat. A downward-facing, Panasonic Lumix DMX-LX100 Mk I (13 MP, Four

170 Thirds sensor) digital camera, was set to photograph at $3 \mathrm{~s}$ intervals with an INON Z240 strobe

171 (Figure S 1.1). The tow-camera was deployed from a $6 \mathrm{~m}$ rigid hulled inflatable boat and

172 minimum of two people conducted the surveys: one adjusted the height of the system to

173 approximately $0.5 \mathrm{~m}$ from the substratum while viewing the live video feed (Bowden \& Jones

174 2016; Carroll et al. 2020) and one drove the boat along the GPS track of the diver transects at a

175 speed of 1-2 knots. Slower speeds were preferable, but the boat needed to move fast enough to

176 stay on track. The optimum time to complete a $50 \mathrm{~m}$ transect, assuming the boat maintained 
177 exact course along the transect, would be 2.5 minutes, corresponding to a speed of $0.33 \mathrm{~ms}^{-1}$

178 (0.65 knots) and with a photo interval of 3 seconds, one photo per 1 metre. Each transect was

179 repeated 2-4 times, to increase image replication, so total survey time for each site was

180 approximately 30-60 minutes. Images were geo-referenced based on the image timestamp

181 matched to the GPS on the boat, which gave an approximation for the position of the tow-

182 camera, which followed behind the boat at approximately 5-10 $\mathrm{m}$ We estimate the distance of the

183 tow-camera from the substrate usually varied between $25-175 \mathrm{~cm}$, meaning the area captured in

184 an individual image likely varied between approximately $13 \times 18 \mathrm{~cm}$ and $81 \times 108 \mathrm{~cm}$.

185 Image selection

186 The tow-camera continuously photographed (every 3 seconds) along the full length of all

187 transects at a site, so individual transects were not distinguished at the time of the tow (Figure 2).

188 Two to four replicates were collected by turning the boat and repeating the same track over the

189 transects. The geo-location of each tow-image was then used to classify each image into one of

190 the transects: polygons were created from the GPS diver track in QGIS to represent each transect

191 with a gap between (see Figure S 1.2). Any images that were in the gap between transects or

192 collected when the boat was turning around were removed. Images from replicated tows were

193 pooled into their respective transects based on image position.

194

195

196

The shortest distance between each tow-camera image and the diver GPS track was measured in

197 metres using 'distance to nearest hub' in QGIS Desktop 3.10.0. The mean and range of distances from the diver track were calculated for each tow and any tow-camera images more than $5 \mathrm{~m}$ from the diver track were removed from further analyses. On the diver transects, one image was taken every metre, i.e. 50 images per $50 \mathrm{~m}$ transect, or 20 images per $20 \mathrm{~m}$ transect (Table 2). For the tow transects, the total number of images varied depending on the number of images within the $5 \mathrm{~m}$ buffer surrounding the diver track, the speed of the boat and the number of replicate tows at a site.

Two observers experienced in coral reef taxonomy analysed the images using point sampling, where the substratum under each of five fixed points overlaid on each image was assigned to the finest taxonomic resolution that could be confidently identified (see Jonker et al. 2008); for corals this was usually to genera.

Benthic data were classified and analysed at two taxonomic scales: (i) the 'benthic community',

210 which grouped all hard corals together and considered the proportions of abiotic substratum, 211 macroalgae, turf/coralline algae and soft corals as separate categories, as well as the proportions

212 of unidentified substratum and points that did not have sufficient image quality to be identified;

213 and (ii) the hard 'coral community'. A combination of genera, family and growth form described 
214 the coral groups to best represent the distinctive groups present at the Rowley Shoals (see Table

$2151)$.

216

217 Covariates

218 We were interested in whether the slope, depth, or substratum complexity accounted for

219 differences between the data from the two methods (Table 2). We used laser airborne depth

220 sounder data (LADS, https://www.navy.gov.au/ran-aviation-history/laser-airborne-depth-

221 sounder-lads), to calculate the mean and standard deviation of depth along the transects, and to

222 estimate substratum complexity. The LADS point cloud was interpolated to form a raster surface

223 using a unidirectional and optimised universal kriging model in the Geostatistical Analyst

224 module in ArcGIS ${ }^{\mathrm{TM}}$ version 10.6. The final raster resolution was $2.66 \mathrm{~m}^{2}$ pixels which was a

225 stable estimation of the variogram model sill point and finer scale interpolation would have

226 introduced stochastic error. From the same LADS raster, we used the ArcGIS ${ }^{\mathrm{TM}}$ surface analysis

227 tool in Spatial Analyst to calculate the mean slope of each transect, as the maximum rate of

228 change between each cell and its neighbours in degrees for a pixel.

229

230 We also considered whether there was a relationship between the number of tow-camera images

231 per metre and the difference between the two methods, to test whether more tow-camera images

232 increased the accuracy of the tow-camera relative to the diver.

233

234 Multivariate statistical analyses

235 Benthic and coral community assemblage data were analysed by transect using multivariate and

236 univariate methods. The percent cover of each benthic group was calculated from the number of

237 points identified to each group in the images divided by the total number of points per transect.

238 All multivariate analyses were conducted in PRIMERv7 (PRIMER-e) using Bray-Curtis

239 dissimilarities calculated from square-root transformed data (Clarke \& Gorley 2015).

240 Community assemblage data were visualised with non-metric multidimensional scaling (nMDS)

241 (Clarke \& Gorley 2015) to examine potential separation between groups associated with the four

242 main factors of interest: method, habitat, reef and year. Vector overlays of Pearson correlations

$243>0.6$ were used to identify the most influential benthic and coral groups driving separation in the

244 data. Additional vector overlays with Pearson correlations $>0.15$ were used to visually assess the

245 extent to which the physical covariates - depth, depth variation or slope - were associated with

246 separation in the data cloud. These physical variables were transformed in cases where their

247 distribution was particularly right skewed: slope and substratum complexity were $\log _{\mathrm{e}}$

248 transformed.

249 
250 We used permutational multivariate analysis of variance (PERMANOVA; Anderson 2001) to

251 test whether method, habitat, reef, survey year, or two-way interactions between these factors

252 affected the composition of benthic and coral communities. Higher order interactions were

253 excluded. Models were reduced by excluding 2-way interactions that had a $p$-value $>0.25$ before

254 re-running the analysis. Residuals were permutated (9999 permutations) under a reduced model,

255 and tests were based on Type III (partial) sums of squares. We tested the hypothesis that the

256 ability of the tow-camera to detect similar benthic and coral community assemblages to the diver

257 method may vary between habitats and therefore specifically examined pairwise tests on the

258 interaction of habitat and method.

259

260 Univariate statistical analyses

261 Differences in the percent cover detected between methods of each of the broad benthic groups

262 and hard coral taxa were investigated using linear models in R (R Development Core Team

263 2018). The analysis was conducted at the transect level and designed to investigate whether

264 mean depth, slope, substratum complexity, habitat and or number of tow-camera images per

265 transect correlated with the difference in the percent cover between the two methods, $\Delta$ cover $_{i, j}$,

266 where

267

268

269

270

271

272

273

274

275

276

277

278

279

280

281

282

283

284

285

286

287

288

and $i$ is the benthic group and $j$ is the transect in question.

$$
\Delta \text { cover }_{i, j}=\text { cover }_{\text {diver }}, j-\text { cover }_{\text {tow }}, j
$$

$\Delta$ cover was modelled as the response variable and habitat, reef and year were included as fixed effects. Site was not included directly in the model, because there was only one site per combination of these fixed effects, and therefore the combination of these factors determined the sites indirectly, thus accounting for spatial autocorrelation of transects. The response variable $\Delta$ cover $_{i, j}$ was bound by a minimum of $-100 \%$ and a maximum of $100 \%$, and a Gaussian error model was used. Homogeneity of variance was checked visually by plotting the residuals against the fitted values. Residuals were examined and were satisfactory for conforming to the normal distribution assumption in most cases. For the coral taxa groups that only appeared on a handful of transects - Diploastrea, Fungiidae, Pavona and unidentified coral - the residuals were not normally distributed, and we did not have confidence in these models, and therefore did not include these statistics. While we may have considered a zero-inflated Gaussian model, or presence-absence models, we did not because there were so few occurrences with which to provide any robust conclusions about these groups. Collinearity among the continuous predictor variables was assessed: slope and substratum complexity were highly correlated $(r>0.75)$ and therefore only slope was included in the models. Predictor variables were transformed to reduce the skewness where appropriate: the slope and the number of images $\mathrm{m}^{-1}$ were $\log _{\mathrm{e}}$-transformed (Table 1). A full model containing all variables was fit first and sequentially simplified based on Akaike Information Criterion (AIC). 
289 We focused on the intercept of the models when predictor variables were at their mean to test 290 whether there was a significant difference between the two methods under average conditions.

291 Therefore, we mean-centred the continuous variables - number of images, slope, and depth - and

292 used sum-to-zero contrast matrices for the categorical variables habitat, year and reef. The model

293 intercepts were directly interpreted as $\Delta$ cover $_{i}$ under average conditions for continuous variables

294 and marginalised over the factors.

295

296

297

In interpreting the results, a mean positive difference in cover $\left(\Delta\right.$ cover $\left._{i}>0\right)$ meant the diver

298 images detected a higher cover of $i$ than the tow-camera images. Conversely, a mean negative

299 difference in cover $\left(\Delta\right.$ cover $\left._{i}<0\right)$ meant the diver images detected a lower cover of $i$ than the towcamera images.

300

301

302

303

\section{Results}

304

The mean distance of the boat towing the camera at the time of image acquisition was 2-3 m

306 either side of the diver transect GPS track (see Figure S 1.3, Figure S 1.4, Table S1.1). Images

307 were excluded from analyses if the boat deviated more than $5 \mathrm{~m}$ from the diver GPS track ( $30 \%$ of 2226 images from the 2018 survey and 22\% of 4194 images from the 2019 survey). The density of remaining images ranged from between 0.3 and 3.4 images $\mathrm{m}^{-1}$, with a mean of 1.3

$310(0.8 \mathrm{SD}) \mathrm{m}^{-1}$, which is more than that of the diver surveys $\left(1 \mathrm{~m}^{-1}\right)$.

\section{Benthic community structure}

313 Variation in benthic community structure was explained by the method of sampling, habitat, reef, 314 survey year and interactions between these factors (Table 3). The main effect of method was 315 significant, indicating that, over and above the interactions, there was an overall difference in

316 benthic community structure detected between the tow-camera and diver methods (Table 3). The 317 greatest components of variation (a measure of the magnitude of the effect) were for the 318 interaction between reef and habitat, and habitat as a main effect (Table 3). A significant

319 method-by-habitat interaction indicates that the differences between the methods varied among 320 the four habitats. Significant differences in the benthic community composition exisited between 321 the sampling methods within all four habitats, but to different extents (Table S 3.1). Among the 322 habitats, the benthic communities separated mainly due to differences in the cover of hard corals; 323 in particular, the reef crest and slope had more hard corals than the lagoon floor and bommies 324 (Figure 3a). Across all transects, the tow-camera method recorded a lower percent cover of 325 crustose coralline algae and hard coral, a higher cover of abiotic substratum, and a higher 
326 proportion of images that could not be assigned to a group due to poor image quality

327 ('unidentified substratum').

328

329 Correlations between the site covariates (slope, substratum complexity, depth) and the

330 multivariate ordination axes were weak (Figure 3a). Univariate analyses indicated that steeper

331 slope (correlated with substratum complexity) was associated with the tow-camera

332 underestimating the cover of hard corals, while obtaining a higher cover that could not be

333 identified (Table S 3.4, Figure 4, Figure 5a). Increases in depth correlated with the tow-camera

334 recording lower cover of crustose coralline algae, and more abiotic substratum relative to the

335 diver method. The two methods become more comparable in their estimates of hard corals as

336 depth increased (Figure 5b).

337

338 Coral community structure

339 The coral community structures identified by the two methods were more similar than the

340 broader benthic community structures (Figure 3, Table 3). As expected, habitat was the most

341 important correlate of variation in coral community structure, but there was also a significant

342 interaction between habitat and method (Pseudo- $F=2.38, \mathrm{df}=3, \mathrm{p}=0.0016$; Table 3 ), indicating

343 differences between the methods depended on the habitat. Pair-wise tests showed no differences

344 in the coral assemblages identified by the two methods at the lagoon floor $(t=1.10, d f,=32, p=$

$3450.32)$ and bommie sites $(t=1.18, d f=30, p=0.25)$, but significant differences at the reef crest $(t$

$346=1.95, \mathrm{df}=31, \mathrm{p}<0.001)$ and reef slope sites $(\mathrm{t}=2.33, \mathrm{df}=55, \mathrm{p}<0.001$; Table $\mathrm{S} 3.1)$.

347

348 The most notable differences in the mean cover of coral taxa between methods was a lower cover

349 of encrusting corals, Isopora, Merulinidae, Millepora and digitate and corymbose Acropora

350 detected by the tow-camera, and a lower cover of tabular Acropora in the diver images (Figure 4,

351 Table S 3.4). Differences in the cover of coral taxa between methods varied among habitats

352 (Figure 6), reefs and survey years (Table S 3.4). For example, the tow-camera surveys detected

353 less cover of encrusting hard corals relative to the diver surveys at bommie sites but more cover

354 of this group at the lagoon floor sites (Figure 6, Table S 3.4). The diver surveys tended to detect

355 more Merulinidae, Millepora, Pocilloporidae, and Porites than the tow-camera (Figure 4, Table

356 S 3.4) as slope increased and more Merulinidae and digitate and corymbose Acropora as depth

357 increased (Figure 5).

358

359 For several benthic and coral groups, an increase in the number of images per metre increased

360 the comparability of the tow-camera data to the diver data (hard coral: $t=0.72, p<0.001$;

361 crustose coralline algae: $\mathrm{t}=0.83, \mathrm{p}<0.001$; abiotic substratum: $\mathrm{t}=0.86, \mathrm{p}<0.001$; Merulinidae:

$362 \mathrm{t}=0.19, \mathrm{p}=0.028 ;$ Millepora: $\mathrm{t}=0.21, \mathrm{p}=0.030$; Figure 5c,f, Table S 3.4).

363

364 
We assessed the suitability of a small towed-camera system for monitoring coral reefs relative to the benchmark of diver photo-transects. The ability of the tow-camera to produce comparable data to diver photo surveys depended on the benthic groups of interest, the physical conditions of survey sites and the number of tow images collected. We attribute image quality (perspective, exposure and focal distance) and limits to the spatial accuracy and precision of the towed-camera system as the two key drivers of differences in the data obtained from the two methods. Our quantitative investigation allows informed suggestions on the best approach to using towedcamera systems for monitoring.

376

A combination of distance of the tow-camera from the substratum and images not being taken perpendicular to the seafloor likely explain the generally negative influence of slope and substratum complexity on the performance of the tow-camera system. Greater substratum complexity required the operator to adjust the depth of the tow-camera more often, leading to more variability in the image quality. Previous studies have also established the challenges of using towed cameras in environments with high rugosity or rough terrain (Durden et al. 2016). The distance between the camera and the substratum will clearly influence image quality and the identification of benthic and coral groups, with diver images collected at a consistent distance of approximately $50 \mathrm{~cm}$ from the substratum, but more variability in the tow-camera images (we estimate 25-150 cm) (Bicknell et al. 2016; Davis et al. 2019; Leonard \& Clark 1993). Our estimates of depth, substratum complexity and slope in the present study were coarse, and finescale measurements of these variables along each transect would have allowed greater insight into the link between tow-camera image quality and the physical attributes of sites. Generally however, the substratum was identifiable to the taxonomic resolution examined in the present study, though identifications from images could take longer when images were poor. Camera systems configured with fast shutter speeds and/or larger depth of field could improve image quality in tow-camera. Automatic image stabilization systems and other evolving technologies will likely improve image capture ability, facilitating use of larger image sensors that can offer

Estimates of benthic community structure differed more between the two methods than for coral assemblages, which can be partly attributed to the morphologies of the benthic and hard coral groups. The tow-camera provided lower estimates of crustose coralline algae and encrusting hard corals, but higher estimates of abiotic substratum. These groups have less distinctive shapes and colours, and less three-dimensional structure than other benthic and coral groups, making them more difficult to distinguish in tow-camera images of lower quality. There were differences in the percent cover of Acropora growth forms detected by the two methods, 
405 possibly reflecting the tow images capturing a greater area per image (greater distance from

406 substratum) and thus detecting more corals with overtopping morphologies, while

407 underestimating encrusting and small or cryptic colonies. Bowden \& Jones (2016) have

408 highlighted that camera orientation is a critical parameter for quantitative interpretation of

409 imagery. In comparing downward- versus forward-facing diver-operated video, Bennett et al.

410 (2016) found more vertically erect corals and algae, but less turf algae in the forward-facing

411 video. In our study, the diver collected images were near-perpendicular to the seafloor,

412 presenting a planar view, whereas there was more variation in the tow-camera image perspective,

413 perhaps meaning 3D forms were more often resolved.

414

415 While divers are mostly able to conduct photo-transect surveys without regard to conditions at

416 the sea surface, maneuvering a vessel to remain on a specified GPS track at low speeds $(<2$

417 knots) while keeping a towed camera tracking along the seabed was more challenging in higher

418 wind and swell conditions, while physical descriptors of the sites (slope, substratum complexity

419 and depth) also influenced image quality. Images $>5 \mathrm{~m}$ either side of the GPS track for each

420 transect were removed from analyses, creating a transect width of $\sim 10 \mathrm{~m}$ for the tow-camera

421 system, i.e., a much wider transect than the 1-2 $\mathrm{m}$ of the diver transects. Therefore, we would

422 expect differences in the data from the two methods simply due their surveying different areas of

423 seafloor. Substantial fine-scale variation and zonation in benthic assemblages can occur over

424 distances of less than $5 \mathrm{~m}$ on coral reefs (Storlazzi et al. 2016; Underwood \& Chapman 1996).

425 As spatial heterogeneity and gradients of community zonation increase, the ability to precisely

426 resurvey the same area becomes more important and can have a large effect on statistical power

427 (Ryan \& Heyward 2003). Indeed, in the present study, a $5 \mathrm{~m}$ deviation perpendicular from a

428 lagoon bommie transect could take the tow-camera system onto the lagoon floor, or a similar

429 deviation from a reef slope transect could take the camera onto the reef flat, or further down the

430 slope into much deeper ( $20 \mathrm{~m})$ water. Another source of variation was the position of the tow-

431 camera relative to the boat, as the position of each image was determined by the location of the

432 boat rather than the tow-camera system, creating additional imprecision in spatial location of the

433 images. A better understanding of where images were collected can be obtained by calculating

434 the position of the camera relative to the boat based on the length and angle of the cable extended

435 (see Carroll et al. 2020), but this does not improve the ability to track along a transect. Coral

436 assemblages detected by the two methods were similar in the lagoon habitats (lagoon floor and

437 bommies) but were significantly different on the reef crest and slope. This may be because the

438 reef slope and crest habitats were more difficult to survey due to the environmental conditions

439 (more exposed) and/or because the coral assemblages are more diverse and can vary over finer

440 spatial scales in these habitats than in the lagoon habitats.

441

442 The divers took approximately 45-60 minutes to complete five end-to-end $50 \mathrm{~m}$ transects,

443 requiring a minimum team of 2 people, while the tow team required the same minimum number

444 of people and a comparable amount of time (30-60 minutes) as transects were repeated 2-4 times

Peer) reviewing PDF | (2020:10:53398:1:1:NEW 19 Feb 2021) 
445 to increase replication. The cost of equipment, maintenance and preparation for surveys, were 446 similar for both methods: a setup for the diver-camera may be in the order of $\$ 2 \mathrm{~K}$, with 447 additional costs for diver equipment up to $\$ 8 \mathrm{~K}$, whereas the cost for the tow-camera system is $448 \$ 7-10 \mathrm{~K}$. The tow-camera is not limited by diver safety restraints, both in terms of the safety of 449 the environment being surveyed (e.g. dangerous marine animals, current, depth) or constraints on 450 dive time. The image analysis tended to be slower for the tow-camera images than the diver 451 images, with suboptimal exposure and focus in some images making it more difficult to 452 distinguish benthic groups quickly, however artificial intelligence may speed the image processing time for both methods in the future (González-Rivero et al. 2020).

\section{Conclusions}

Tow-camera systems offer an alternative approach to monitoring shallow water coral reefs, but with important trade-offs and situation- and location-dependent considerations. The same level of spatial accuracy and precision as a diver on a fixed transect cannot be achieved with the towcamera, making it difficult or impossible to monitor at a level where the same communities are likely to be revisited in repeated sampling. In the present study, sampling with the tow-camera was constrained by applying the same sampling design as was used in the diver surveys, to make comparisons between the methods as rigorous as possible. However, we suggest the tow-camera would be better applied to monitoring with a dedicated sampling design reflecting the strengths and weaknesses of the system. Given the spatial variability when attempting to follow a linear transect with the tow-camera, and the result that an increase in the number of images improved compatibility with the diver data, we suggest more heavily sampling (more images) an area that defines a region of interest. Variations of the tow-camera system used in the present study have been used to sample large areas $\left(\mathrm{km}^{2}\right)$ to produce benthic habitat maps and models for shallow and deep coral reefs (Heyward \& Radford 2019). For monitoring, variability and zonation in habitats are key considerations for a revised sampling design as this approach would be of limited success if the area being sampled spanned different habitats (e.g. reef slope to reef crest; bommies to lagoon floor) or was highly heterogeneous. The size of the survey area is therefore important; for example Jokiel et al. (2015) showed that longer transects ( $25 \mathrm{~m}$ and $50 \mathrm{~m}$ ) were useful for relatively homogeneous substratum but shorter transects $(10 \mathrm{~m})$ were more appropriate in heterogeneous habitats. Therefore, a georeferenced polygon within habitats of interest in the order of 0.1-1.0 hectares in area, large enough to maneuver a small boat within, might be most successful.

We would suggest any established diver-based long-term monitoring programs should maintain continuity in methods where possible, given the tow-camera could not achieve the same results, with implications for sampling design and statistical power. Nonetheless, the tow-camera is an alternative for surveying shallow reef environments when it is not possible for divers to enter the 
485

486

487

488

489

490

491

492

493

494

495

496

497

498

499

500

501

502

503

504

505

506

507

508

509

510

511

512

513

514

515

516

517

518

519

520

521

522

523

524

525

526

water. The comparison presented here will allow informed interpretation of future data collected by tow-cameras and a clearer understanding of the strengths, weaknesses and biases relative to diver-camera data.

\section{Acknowledgements}

We would like to thank Diego Barneche and Rebecca Fisher for discussions on statistical analyses; the crew and field teams on the RV Solander on both the field trips when this data was collected, in particular Kim Brooks; the workshop team in Townsville for maintaining the towcamera system and Neill Roberts and Melanie Olsen for writing a Standard Operating Procedure for this tow-camera, and providing the schematic shown in an appendix. An earlier version of the manuscript benefited from comments provided by Karen Miller, Scott Bainbridge and Vicki Nelson.

\section{References}

Anderson MJ. 2001. A new method for non-parametric multivariate analysis of variance. Austral ecology 26:32-46.

Barker BA, Helmond I, Bax NJ, Williams A, Davenport S, and Wadley VA. 1999. A vesseltowed camera platform for surveying seafloor habitats of the continental shelf. Continental Shelf Research 19:1161-1170.

Bennett K, Wilson SK, Shedrawi G, McLean DL, and Langlois TJ. 2016. Can diver operated stereo-video surveys for fish be used to collect meaningful data on benthic coral reef communities? Limnology and Oceanography: Methods 14:874-885. 10.1002/lom3.10141

Bicknell AW, Godley BJ, Sheehan EV, Votier SC, and Witt MJ. 2016. Camera technology for monitoring marine biodiversity and human impact. Frontiers in Ecology and the Environment 14:424-432.

Boavida J, Assis J, Reed J, Serrão EA, and Gonçalves JM. 2016. Comparison of small remotely operated vehicles and diver-operated video of circalittoral benthos. Hydrobiologia 766:247-260.

Bowden DA, and Jones DO. 2016. Towed cameras. In: Clark MR, M. C, and A. RA, eds. Biological Sampling in the Deep Sea: John Wiley \& Sons, 260-284.

Brown EK, Cox E, Jokiel P, Rodgers SKu, Smith WR, Tissot BN, Coles SL, and Hultquist J. 2004. Development of benthic sampling methods for the Coral Reef Assessment and Monitoring Program (CRAMP) in Hawai'i. Pacific Science 58:145-158.

Carleton J, and Done T. 1995. Quantitative video sampling of coral reef benthos: large-scale application. Coral Reefs 14:35-46.

Carroll A, Althaus F, Beaman R, Friedman A, Ierodiaconou D, Ingleton T, Jordan A, Linklater M, Monk J, Post A, Przeslawski R, Smith J, Stowar M, Tran M, Tyndall A. 2020. Marine sampling field manual for towed underwater camera systems. In: Przeslawski R, and 
Foster S, eds. Field manuals for marine sampling to monitor Australian waters, Version 2. Canberra, Australia: NESP Marine Biodiversity Hub.

Clarke K, and Gorley R. 2015. Getting started with PRIMER v7. PRIMER-E Ltd. Plymouth, UK: Plymouth Marine Laboratory. p 20.

Cruz-Marrero W, Cullen DW, Gay NR, and Stevens BG. 2019. Characterizing the benthic community in Maryland's offshore wind energy areas using a towed camera sled: Developing a method to reduce the effort of image analysis and community description. PLOS ONE 14:e0215966.

Davis T, Cadiou G, Williams J, and Coleman M. 2019. Costs and benefits of towed videos and remotely operated vehicles for sampling shallow reef habitats and fish. Marine and Freshwater Research.

Durden JM, Schoening T, Althaus F, Friedman A, Garcia R, Glover AG, Greinert J, Stout NJ, Jones DO, and Jordt A. 2016. Perspectives in visual imaging for marine biology and ecology: from acquisition to understanding. Oceanography and marine biology: an annual review 54:1-72.

Edmunds PJ. 2013. Decadal-scale changes in the community structure of coral reefs of St. John, US Virgin Islands. Marine Ecology Progress Series 489:107-123.

Flannery E, and Przeslawski R. 2015. Comparison of sampling methods to assess benthic marine biodiversity. Are spatial and ecological relationships consistent among sampling gear? Canberra, Australia.

Foster SD, Hosack GR, Hill NA, Barrett NS, and Lucieer VL. 2014. Choosing between strategies for designing surveys: autonomous underwater vehicles. Methods in Ecology and Evolution 5:287-297.

Galzin R, Lecchini D, Lison de Loma T, Moritz C, Parravicini V, and Siu G. 2016. Long term monitoring of coral and fish assemblages (1983-2014) in Tiahura reefs, Moorea, French Polynesia. Cybium 40:31-41.

Gilmour JP, Cook KL, Ryan NM, Puotinen ML, Green RH, Shedrawi G, Hobbs J-PA, Thomson DP, Babcock RC, and Buckee J. 2019. The state of Western Australia's coral reefs. Coral Reefs 38:651-667.

González-Rivero M, Beijbom O, Rodriguez-Ramirez A, Bryant DEP, Ganase A, GonzalezMarrero Y, Herrera-Reveles A, Kennedy EV, Kim CJS, Lopez-Marcano S, Markey K, Neal BP, Osborne K, Reyes-Nivia C, Sampayo EM, Stolberg K, Taylor A, Vercelloni J, Wyatt M, and Hoegh-Guldberg O. 2020. Monitoring of Coral Reefs Using Artificial Intelligence: A Feasible and Cost-Effective Approach. Remote Sensing 12:489.

Heyward A, and Radford B. 2019. Northwest Australia. In: Loya Y, Puglise KA, and Bridge TCL, eds. Mesophotic Coral Ecosystems: Springer, 337-349.

Houk P, and Van Woesik R. 2006. Coral reef benthic video surveys facilitate long-term monitoring in the Commonwealth of the Northern Mariana Islands: toward an optimal sampling strategy. Pacific Science 60:177-189.

Houk P, and Van Woesik R. 2013. Progress and perspectives on question-driven coral-reef monitoring. BioScience 63:297-303.

Hughes TP, Anderson KD, Connolly SR, Heron SF, Kerry JT, Lough JM, Baird AH, Baum JK, Berumen ML, and Bridge TC. 2018. Spatial and temporal patterns of mass bleaching of corals in the Anthropocene. Science 359:80-83. 
571

572

573

574

575

576

577

578

579

580

581

582

583

584

585

586

587

588

589

590

591

592

593

594

595

596

597

598

599

600

601

602

603

604

605

606

607

608

609

610

611

612

613

614

615

616

Jokiel PL, Rodgers KS, Brown EK, Kenyon JC, Aeby G, Smith WR, and Farrell F. 2015. Comparison of methods used to estimate coral cover in the Hawaiian Islands. PeerJ 3:e954.

Jones DO, Bett BJ, Wynn RB, and Masson DG. 2009. The use of towed camera platforms in deep-water science. Underwater Technology 28:41-50.

Jonker M, Johns K, and Osborne K. 2008. Surveys of benthic reef communities using underwater digital photography and counts of juvenile corals. Long-term Monitoring of the Great Barrier Reef, Standard Operational Procedure No 10. Townsville, Australia: Australian Institute of Marine Science.

Lam K, Shin PK, Bradbeer R, Randall D, Ku KK, Hodgson P, and Cheung SG. 2006. A comparison of video and point intercept transect methods for monitoring subtropical coral communities. Journal of Experimental Marine Biology and Ecology 333:115-128.

Lembke C, Grasty S, Silverman A, Broadbent H, Butcher S, and Murawski S. 2017. The Camera-Based Assessment Survey System (C-BASS): A towed camera platform for reef fish abundance surveys and benthic habitat characterization in the Gulf of Mexico. Continental Shelf Research 151:62-71.

Leonard GH, and Clark RP. 1993. Point quadrat versus video transect estimates of the cover of benthic red algae. Marine Ecology-Progress Series 101:203-203.

Leujak W, and Ormond R. 2007. Comparative accuracy and efficiency of six coral community survey methods. Journal of Experimental Marine Biology and Ecology 351:168-187.

Littler MM, Littler DS, Brooks BL, and Koven JF. 1997. A unique coral reef formation discovered on the Great Astrolabe Reef, Fiji. Coral Reefs 16:51-54.

Ludvigsen M, and Sørensen AJ. 2016. Towards integrated autonomous underwater operations for ocean mapping and monitoring. Annual Reviews in Control 42:145-157.

McDonald-Madden E, Baxter PW, Fuller RA, Martin TG, Game ET, Montambault J, and Possingham HP. 2010. Monitoring does not always count. Trends in Ecology \& Evolution 25:547-550.

Mellin C, Peterson EE, Puotinen M, and Schaffelke B. 2020. Representation and complementarity of the long-term coral monitoring on the Great Barrier Reef. Ecological Applications doi: 10.1002/eap.2122. 10.1002/eap.2122

Mohamed H, Nadaoka K, and Nakamura T. 2020. Towards Benthic Habitat 3D Mapping Using Machine Learning Algorithms and Structures from Motion Photogrammetry. Remote Sensing 12:127.

Obura D, Gudka M, Abdou Rabi F, Bacha Gian S, Bigot L, Bijoux J, Freed S, Maharavo J, Munbodhe V, and Mwaura J. 2017. Coral reef status report for the Western Indian Ocean. Global Coral Reef Monitoring Network (GCRMN). International Coral Reef Initiative (ICRI) 144.

R Development Core Team. 2018. R: A language and environment for statistical computing. $\mathrm{R}$ Foundation for Statistical Computing. 3.4.4 ed. Vienna, Austria: R Foundation for Statistical Computing.

Raoult V, Tosetto L, Harvey C, Nelson TM, Reed J, Parikh A, Chan AJ, Smith TM, and Williamson JE. 2020. Remotely operated vehicles as alternatives to snorkellers for videobased marine research. Journal of Experimental Marine Biology and Ecology $522: 151253$.

Richards ZT, and Day JC. 2018. Biodiversity of the Great Barrier Reef-how adequately is it protected? PeerJ 6:e4747.

Peer) reviewing PDF | (2020:10:53398:1:1:NEW 19 Feb 2021) 
617 Ryan DA, and Heyward A. 2003. Improving the precision of longitudinal ecological surveys 618 using precisely defined observational units. Environmetrics: The official journal of the 619 International Environmetrics Society 14:283-293.

Sheehan EV, Vaz S, Pettifer E, Foster NL, Nancollas SJ, Cousens S, Holmes L, Facq JV, Germain G, and Attrill MJ. 2016. An experimental comparison of three towed underwater video systems using species metrics, benthic impact and performance. Methods in Ecology and Evolution 7:843-852.

Storlazzi CD, Dartnell P, Hatcher GA, and Gibbs AE. 2016. End of the chain? Rugosity and fine-scale bathymetry from existing underwater digital imagery using structure-frommotion (SfM) technology. Coral Reefs 35:889-894.

Sward D, Monk J, and Barrett N. 2019. A Systematic Review of Remotely Operated Vehicle Surveys for Visually Assessing Fish Assemblages. Frontiers in Marine Science 6. 10.3389/fmars.2019.00134

Sweatman H, Burgess S, Cheal A, Coleman G, Delean JSC, Emslie M, Miller I, Osborne K, McDonald A, and Thompson A. 2005. Long-term monitoring of the Great Barrier Reef.

Underwood A, and Chapman M. 1996. Scales of spatial patterns of distribution of intertidal invertebrates. Oecologia 107:212-224.

Wilson B. 2013. Chapter 4 - Coral Reefs of the North West Shelf. In: Wilson B, ed. The Biogeography of the Australian North West Shelf. Boston: Elsevier, 107-201.

Zinke J, Gilmour JP, Fisher R, Puotinen M, Maina J, Darling E, Stat M, Richards ZT, McClanahan TR, Beger M, Moore C, Graham NAJ, Feng M, Hobbs J-PA, Evans SN, Field S, Shedrawi G, Babcock RC, and Wilson SK. 2018. Gradients of disturbance and environmental conditions shape coral community structure for south-eastern Indian Ocean reefs. Diversity and Distributions 24:605-620. doi:10.1111/ddi.12714

Zuur AF, Ieno EN, and Elphick CS. 2010. A protocol for data exploration to avoid common statistical problems. Methods in Ecology and Evolution 1:3-14. 


\section{Table $\mathbf{1}$ (on next page)}

Categories used to describe the benthic communities and the coral communities at the Rowley Shoals 


\begin{tabular}{|c|c|}
\hline Category & Description and occurrence at Rowley Shoals \\
\hline \multicolumn{2}{|l|}{ Benthic community } \\
\hline $\begin{array}{l}\text { Crustose coralline } \\
\text { algae }\end{array}$ & Crustose coralline algae and fine turf algae, suitable for colonisation by coral recruits \\
\hline Macroalgae & $\begin{array}{l}\text { Large fleshy algae, which are rare across the reef system, but if present can exclude } \\
\text { and outcompete coral recruits }\end{array}$ \\
\hline Soft coral & $\begin{array}{l}\text { Lobophytum and Sinularia. Found at all three reefs but most common at Mermaid } \\
\text { Reef }\end{array}$ \\
\hline Hard coral & Scleractinian corals and Millepora (fire coral) \\
\hline Abiotic substratum & Sand, rubble, dead coral, shells \\
\hline Other organisms & Ascidians, hydroids (not Millepora), non-mobile gastropods, zoanthids \\
\hline Sponge & Relatively rare at the depths studied \\
\hline $\begin{array}{l}\text { Unidentified } \\
\text { substratum }\end{array}$ & $\begin{array}{l}\text { No benthic ID was possible from the point on the photo due to image quality or } \\
\text { obstruction by diver, tape or mobile organisms; Image very blurry or not directed at } \\
\text { the substratum (e.g. only shows water) }\end{array}$ \\
\hline \multicolumn{2}{|l|}{ Coral community } \\
\hline $\begin{array}{l}\text { Corymbose and digitate } \\
\text { Acropora }\end{array}$ & Corymbose and digitate growth forms common across the Rowley Shoals \\
\hline Tabular Acropora & Tabulate growth forms common across the Rowley Shoals \\
\hline Branching Acropora & Branching growth forms common across the Rowley Shoals \\
\hline Astreopora & Rare, but some present on the Mermaid lagoon floor \\
\hline Diploastrea & Characteristic of Mermaid Reef \\
\hline Foliose corals & Echinopora, Merulina, Pachyseries, Pectinia, Turbinaria \\
\hline Fungiidae & Rare, but some present at Mermaid lagoon floor. Fungia \\
\hline Isopora & Isopora brueggemanni and I. palifera \\
\hline Merulinidae & $\begin{array}{l}\text { Goniastrea, Coelastrea, Dipsastrea (formerly Favia), Favites, Cyphastrea and other } \\
\text { Merulinidae species, mostly with a massive growth form. Corals from the genus } \\
\text { Leptastrea (L. insertae, L. sedis) are also included in this group. }\end{array}$ \\
\hline Encrusting corals & $\begin{array}{l}\text { Encrusting forms of Montipora, Acanthastrea, Acropora, Galaxea, Merulina, } \\
\text { Pectinia, Psammocora and Turbinaria }\end{array}$ \\
\hline Pavona & Including encrusting and submassive growth forms \\
\hline Pocilloporidae & Pocillopora, Seriatopora, Stylophora \\
\hline Porites & Mostly massive forms, with branching morphology rare \\
\hline Millepora & Hydrozoa within the Family Milleporidae \\
\hline Soft corals & $\begin{array}{l}\text { Lobophytum and Sinularia. Found at all three reefs but most common at Mermaid } \\
\text { Reef }\end{array}$ \\
\hline $\begin{array}{l}\text { Uncommon (grouped } \\
\text { for univariate analyses, } \\
\text { included as separate } \\
\text { groups in multivariate } \\
\text { analyses) }\end{array}$ & $\begin{array}{l}\text { Other hard coral genera not included above that were present but had less than a } \\
\text { maximum of } 2 \% \text { cover across all eight sites such that we would not expect them to be } \\
\text { reliably detected by either survey method (Coeloseris, Galaxea, Gardineroseris, } \\
\text { Goniopora, Hydnophora, Lobophyllia, Merulina, Montastrea, Oulophyllia, } \\
\text { Pachyseris, Pectinia, Plerogyra, Plesiastrea, Psammocora, Symphyllia, Turbinaria) }\end{array}$ \\
\hline Unidentified coral & $\begin{array}{l}\text { A coral, but classification into one of the above groups was not possible from the } \\
\text { image }\end{array}$ \\
\hline
\end{tabular}




\section{Table 2 (on next page)}

Covariates considered in statistical models. Transformations are given in square brackets 


\begin{tabular}{llll}
\hline $\begin{array}{l}\text { Variables } \\
\text { (transformation) }\end{array}$ & $\begin{array}{l}\text { Degrees of } \\
\text { freedom }\end{array}$ & Values / range & Fixed or random \\
\hline Method & 1 & Diver or Tow & Fixed \\
\hline Habitat & 3 & $\begin{array}{l}\text { Slope, Crest, } \\
\text { Lagoon floor, } \\
\text { Bommie }\end{array}$ & Fixed \\
\hline Reef & 2 & $\begin{array}{l}\text { Mermaid, Clerke, } \\
\text { Imperieuse }\end{array}$ & Fixed \\
\hline Survey year & 2 & 2018 or 2019 & Fixed \\
\hline Depth $(\mathrm{m})$ & 1 & $0.35-11$ & Fixed \\
\hline Substratum complexity & 1 & $0.06-2.83$ & Fixed \\
\hline Slope $\left[\log _{\mathrm{e}}\right]$ & 1 & $2.3-45.6$ & Fixed \\
\hline Number of images $\left(\mathrm{m}^{-1}\right)$ & 1 & $\begin{array}{l}\text { Diver: Mean } 2.5, \\
\text { range 0.3-3.4 }\end{array}$ & Fixed \\
{$\left[\log _{\mathrm{e}}\right]$} & & $\begin{array}{l}\text { Tow: Mean 1, } \\
\text { range 1-1 }\end{array}$ & \\
\hline
\end{tabular}

\section{1}




\section{Table 3 (on next page)}

PERMANOVA partitioning and analysis of the benthic (8 categories) and coral community (16 categories) assemblages at the Rowley Shoals, based on square-root transformed percent cover and Bray-Curtis dissimilarities.

'Source' $=$ sources of variation in the model, 'df' $=$ degrees of freedom, 'SS' $=$ sums of squares, 'MS' = mean squares, 'Pseudo- $F$ ' is the pseudo F-ratio and ' $\mathrm{p}$ ' $=$ permutation Pvalue. 'Variance' estimates sizes of components of variation based on multivariate analogues to the classical ANOVA unbiased estimators. 'Sq.root' gives the square root of these values, so is in Bray-Curtis units. In the Source column, ME = method; $H A B=$ habitat; $Y R=$ survey year; RE = reef. Significant effects are indicated in bold. 


\begin{tabular}{lllllllll}
\hline Source & $\mathrm{df}$ & $\mathrm{SS}$ & $\mathrm{MS}$ & Pseudo-F & $\mathrm{p}$ & Component & Variance & Sq.root \\
\hline \multicolumn{1}{l}{ Benthic community } & & & & & & & \\
\hline ME & 1 & 2370.0 & 2370.0 & 27.79 & $\mathbf{0 . 0 0 0 1}$ & Fixed & 35.7 & 6.0 \\
HAB & 3 & 17597.0 & 5865.6 & 68.79 & $\mathbf{0 . 0 0 0 1}$ & Fixed & 153.3 & 12.4 \\
RE & 2 & 3737.1 & 1868.6 & 21.91 & $\mathbf{0 . 0 0 0 1}$ & Fixed & 38.4 & 6.2 \\
YR & 1 & 761.4 & 761.4 & 8.93 & $\mathbf{0 . 0 0 0 2}$ & Fixed & 9.4 & 3.1 \\
MExHAB & 3 & 3295.0 & 1098.3 & 12.88 & $\mathbf{0 . 0 0 0 1}$ & Fixed & 53.4 & 7.3 \\
MExRE & 2 & 650.2 & 325.1 & 3.81 & $\mathbf{0 . 0 0 3 1}$ & Fixed & 9.7 & 3.1 \\
MExYR & 1 & 2823.9 & 2823.9 & 33.12 & $\mathbf{0 . 0 0 0 1}$ & Fixed & 68.9 & 8.3 \\
HABxRE & 4 & 7933.1 & 1983.3 & 23.26 & $\mathbf{0 . 0 0 0 1}$ & Fixed & 118.2 & 10.9 \\
RExYR & 2 & 573.8 & 286.9 & 3.36 & $\mathbf{0 . 0 0 5 9}$ & Fixed & 7.9 & 2.8 \\
Res & 146 & 12450 & 85.3 & - & - & Random & 85.3 & 9.2 \\
Total & 165 & 57200 & - & - & - & - & - & - \\
\hline Coral community & & & & & & & \\
\hline ME & 1 & 568.5 & 568.5 & 1.18 & 0.3489 & Fixed & 1.1 & 1.0 \\
HAB & 3 & 71538.0 & 23846.0 & 49.47 & $\mathbf{0 . 0 0 0 1}$ & Fixed & 643.8 & 25.4 \\
RE & 2 & 17302.0 & 8651.0 & 17.95 & $\mathbf{0 . 0 0 0 1}$ & Fixed & 172.9 & 13.1 \\
YR & 1 & 1311.6 & 1311.6 & 2.72 & $\mathbf{0 . 0 1 4 1}$ & Fixed & 11.2 & 3.3 \\
MExHAB & 3 & 3445.1 & 1148.4 & 2.38 & $\mathbf{0 . 0 0 1 6}$ & Fixed & 32.8 & 5.7 \\
HABxRE & 4 & 17878.0 & 4469.4 & 9.27 & $\mathbf{0 . 0 0 0 1}$ & Fixed & 246.7 & 15.7 \\
HABxYR & 3 & 4091.1 & 1363.7 & 2.83 & $\mathbf{0 . 0 0 0 1}$ & Fixed & 45.7 & 6.8 \\
Res & 148 & 71347 & 482.1 & - & - & Random & 482.1 & 22.0 \\
Total & 165 & 205000 & - & - & - & - & - & - \\
& & & & & & & &
\end{tabular}


Figure 1

Site map

Location of the Rowley Shoals in northwest Western Australian (left). Study sites and habitats (right).

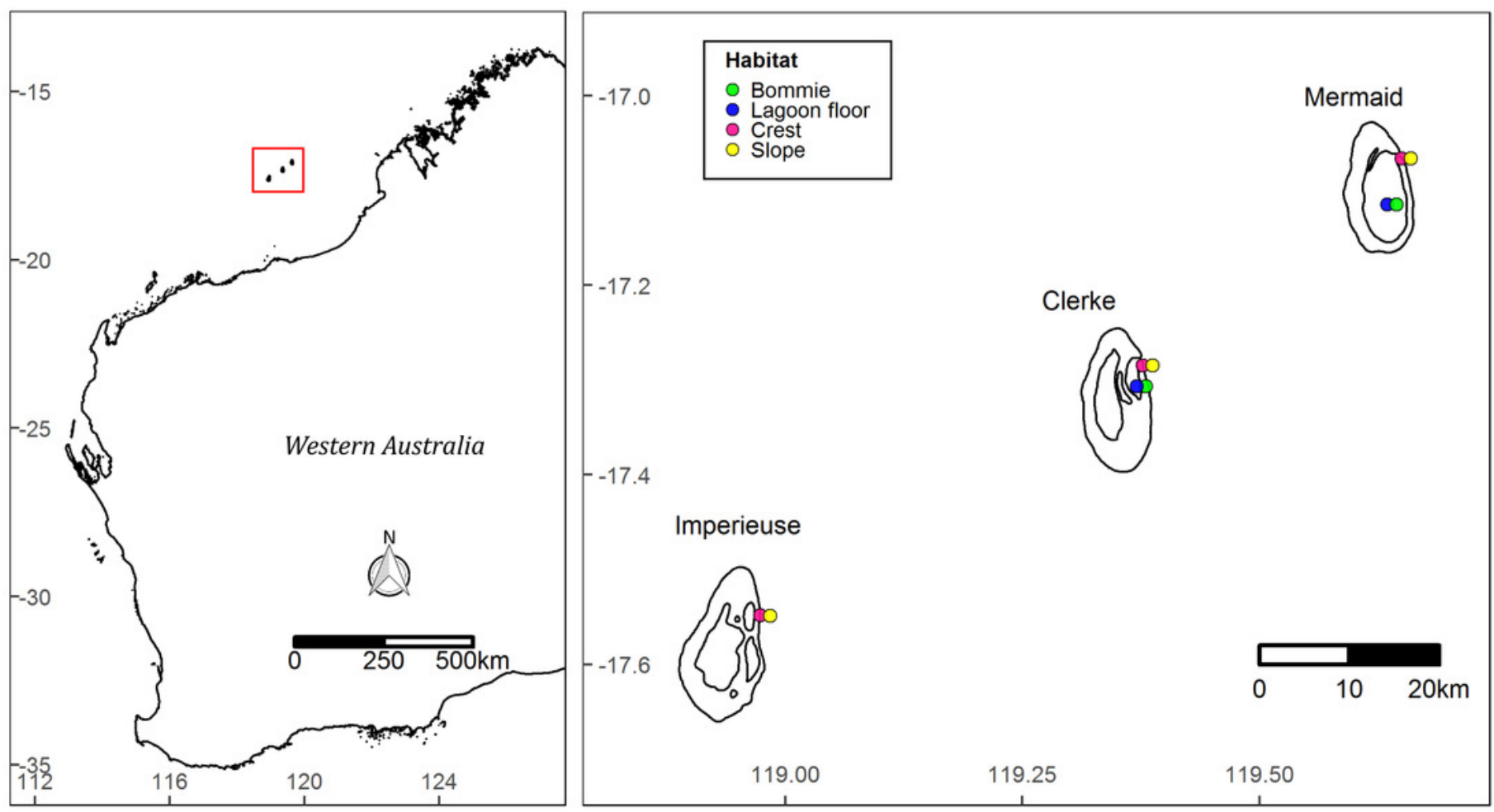




\section{Figure 2}

Schematic of transects

Schematic showing examples of fixed, 50 m-long diver transects (red), separated by $10 \mathrm{~m}$, for a reef crest and reef slope site. A continuous GPS track of these transects was followed using the tow-camera with images continuously collected every 3 seconds (e.g. blue track), a process which was replicated 2 to 4 times. Diagram modified from Sweatman et al. (2005).

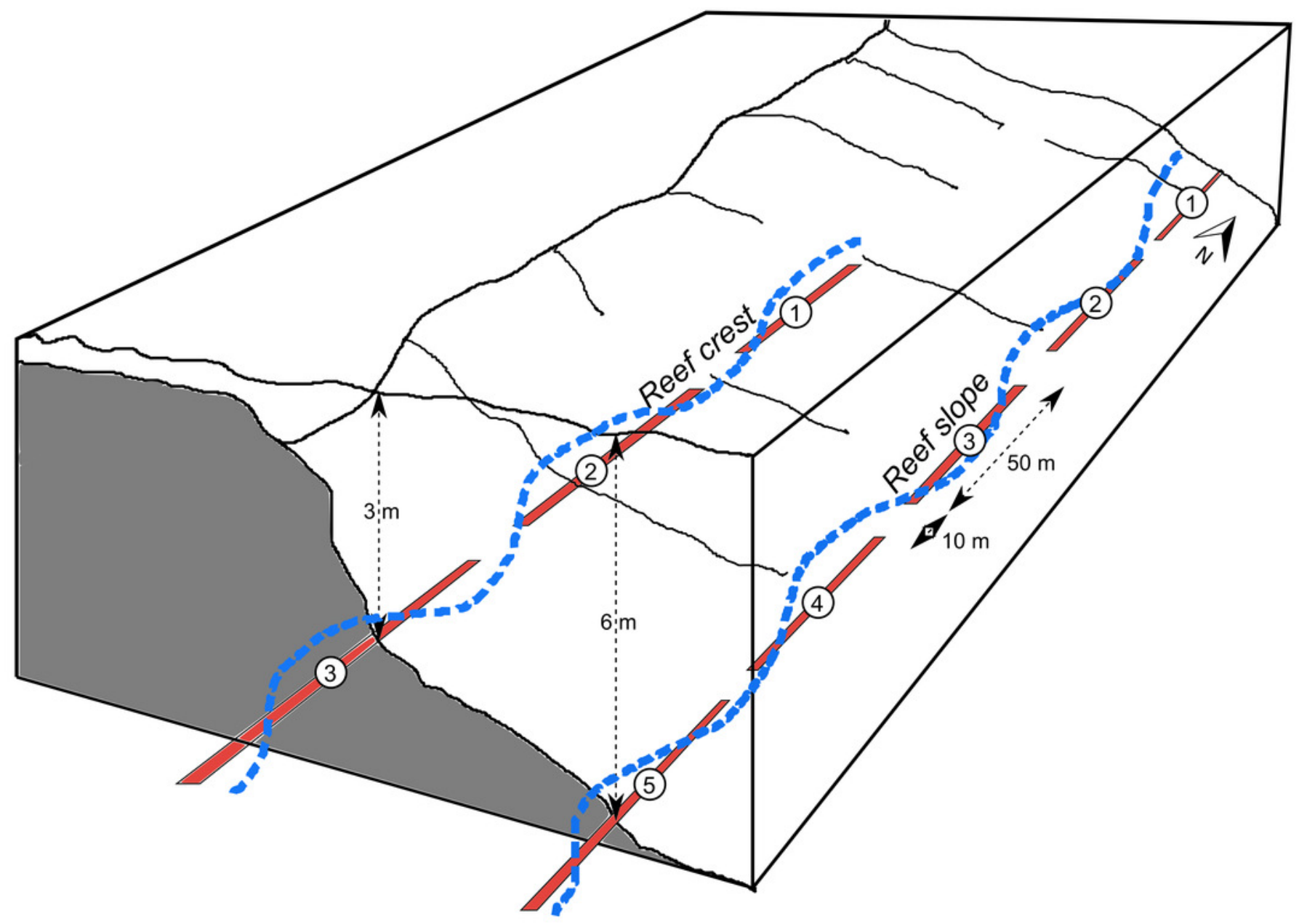




\section{Figure 3}

nMDS of A) the benthic community structure and B) the coral community structure.

nMDS of $A$ ) the benthic community structure and $B$ ) the coral community structure. Black outlined circles represent the diver transects whereas the downwards facing grey triangles represent tow-camera transects. The dashed ellipses indicate $95 \%$ spatial confidence intervals for the centroids of the two methods with overlap therefore indicating similarity in the assemblages identified. Colour identifies the four habitats surveyed. Vectors with Pearson correlations $>0.6$ and $>0.15$ for biological and environmental variables respectively are shown to the right of the nMDS plots to indicate the main benthic/coral groups (centre) and depth, slope and structural complexity parameters (right) causing separation in the data cloud. 


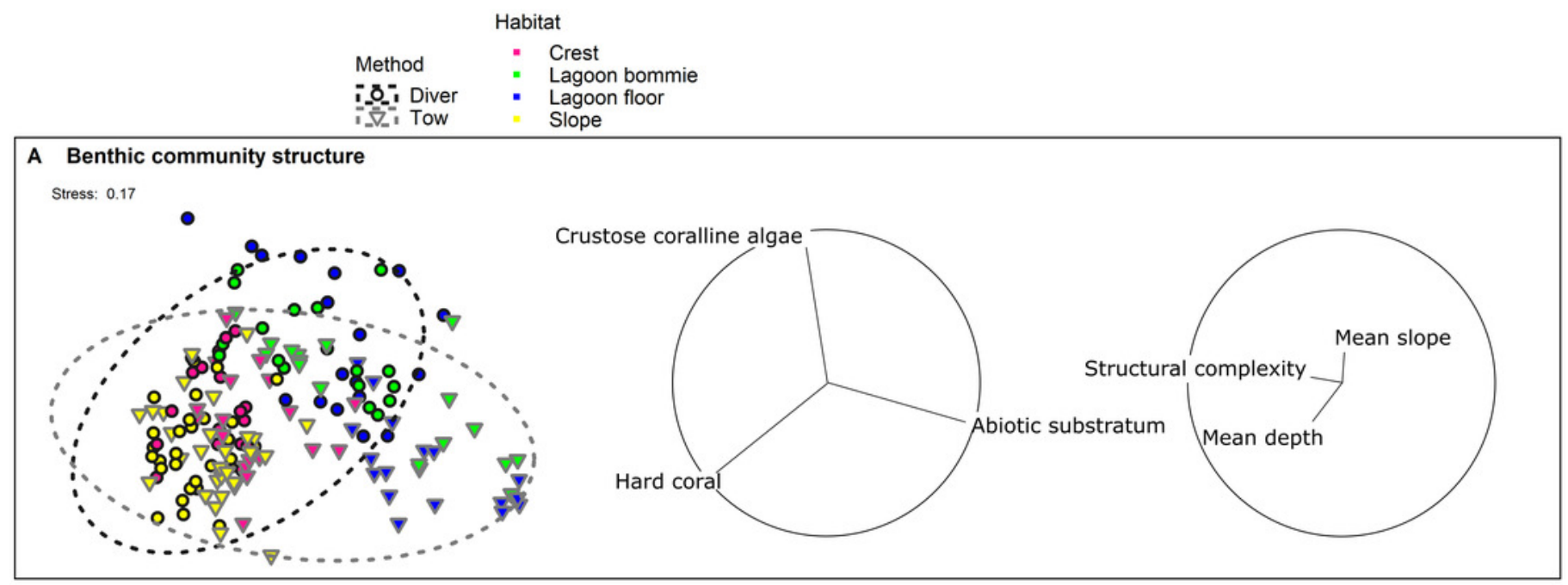

B Coral community structure

Stress: 0.16
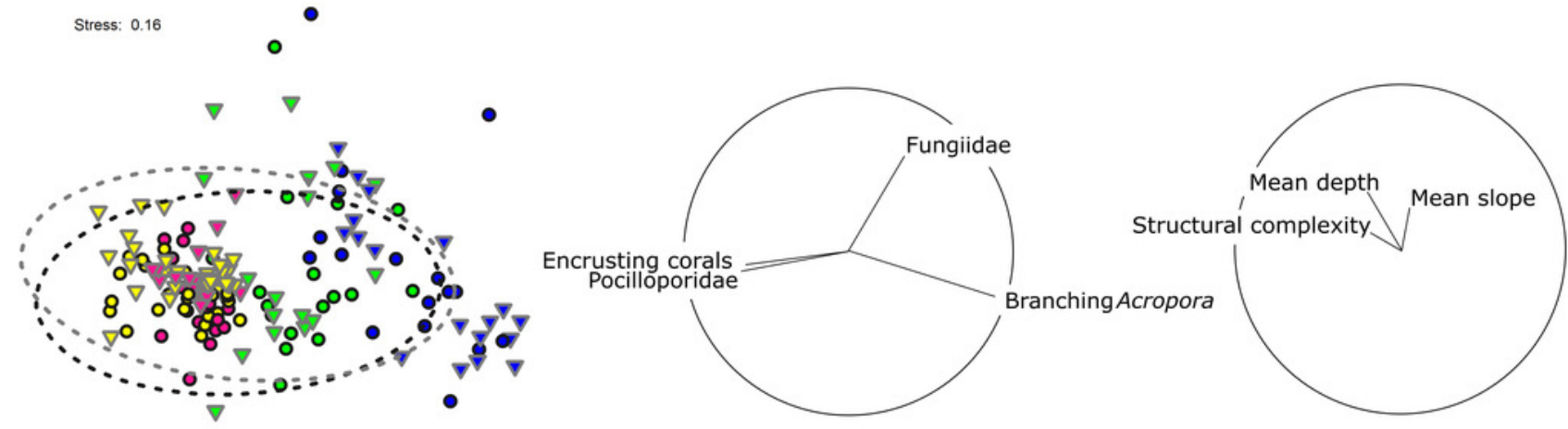
Figure 4

Comparison of percent cover between methods

Stacked bar plots with blocks representing the mean percent cover of each A) benthic and B) coral group for the diver and the tow-camera survey methods, with stream fields between the bars illustrating the difference between the methods. Asterisks in legend indicate a significant difference between the two methods as identified from linear models when all predictor variables were at their mean $(* * * p<0.001, * * p<0.01, * p<0.05$; $(n / a)$ is specified when the data did not meet the assumptions for robust linear modelling). See table S.3.2 for associated mean and standard error values.
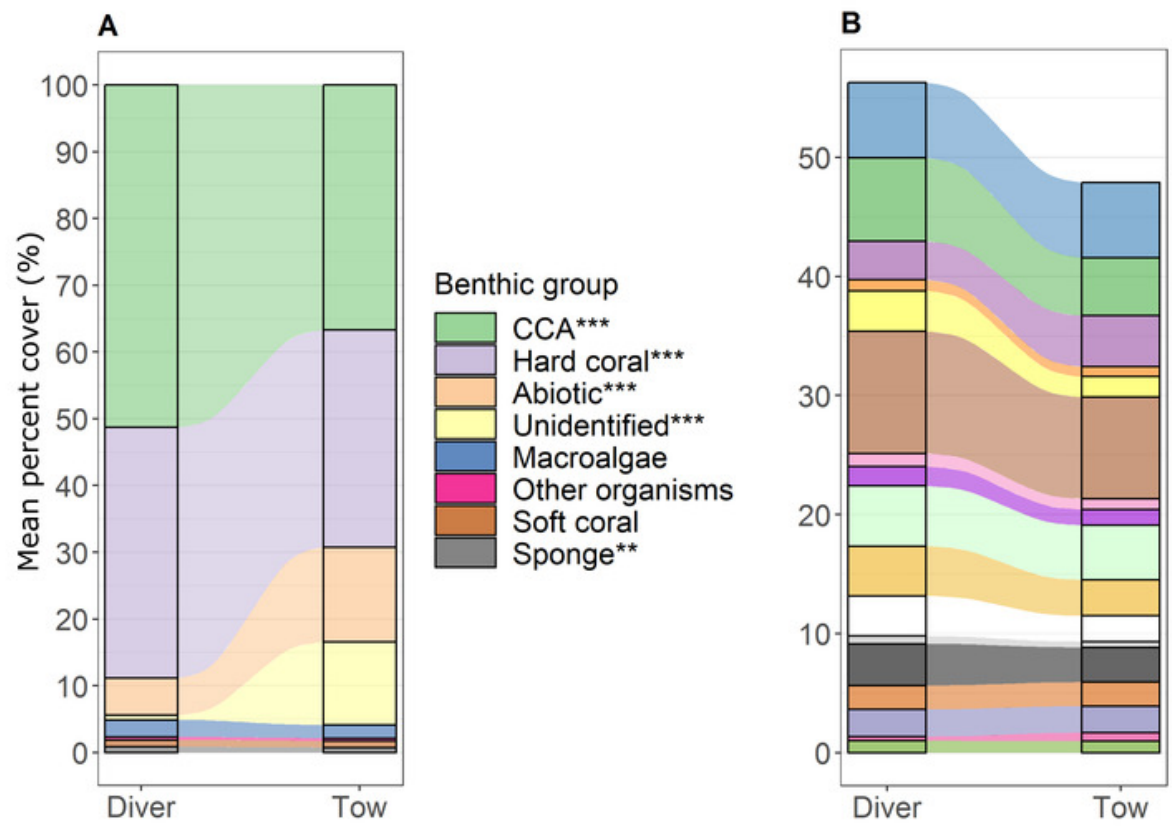

Coral group

$\square$ Branching Acropora *ᄎ*

Digitate/ corymbose Acropora***

Tabular Acropora***

Astreopora*

Diploastrea (n/a)

Encrusting corals*

Foliose corals

Fungiidae (n/a)

Isopora

Merulinidae ${ }^{\star \star \star}$

Millepora ${ }^{* * *}$

Pavona (n/a)

Pocilloporidae

Porites ${ }^{\star \star \star}$

Soft coral

Unidentified coral (n/a)

Uncommon ${ }^{\star \star \star}$ 
Figure 5

Predictions from linear models

Predictions from the top linear models for the common benthic and coral groups. Marginal effects of each continuous variable at the mean of the factor variables are shown to indicate how these variables relate to the difference between the two survey methods where $\Delta$ cover $_{\mathrm{i}}$ is calculated as diver - tow-camera.

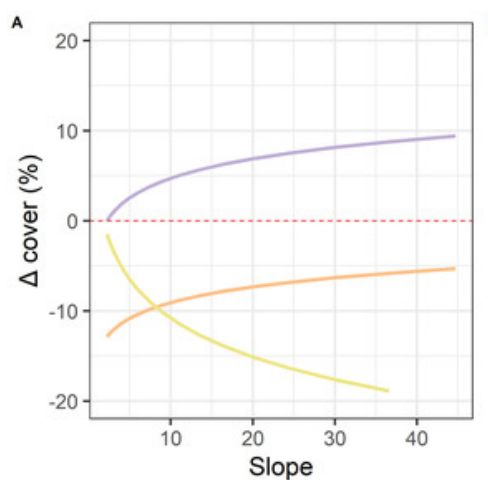

D

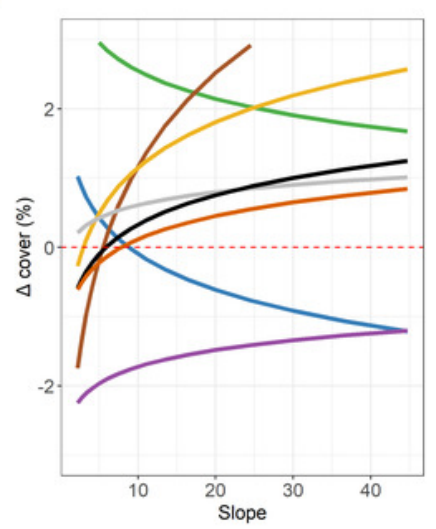

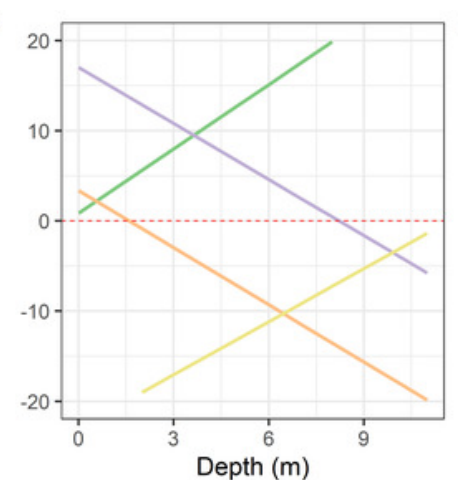

E

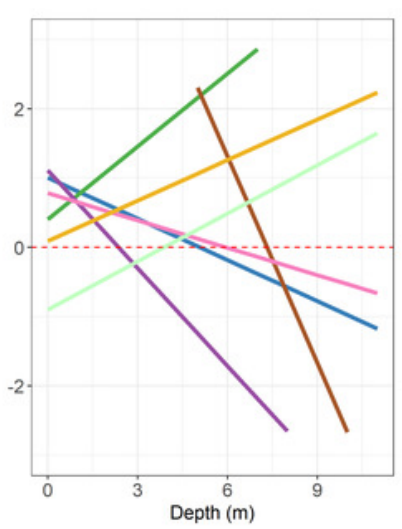

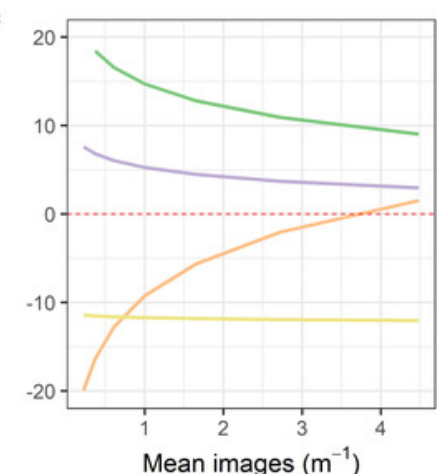

F

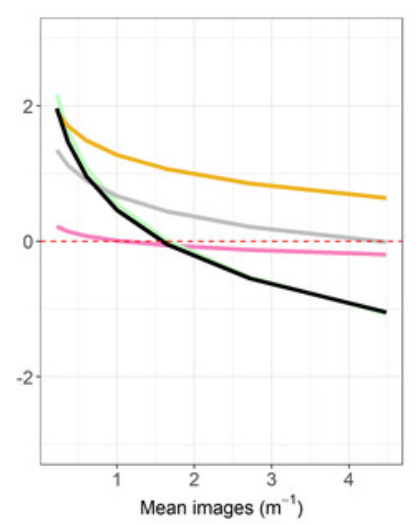

Benthic group

- CCA

Abiotic

Unidentified

Unidentified
Coral group

- Branching Acropora

- Digitate/ corymbose Acropora

Tabutar Acropora

Encrusting corals

Foliose corals

Isopora

Merulinidae

Millepora

- Pocilloporidae

- Porites 
Figure 6

Boxplots of habitat differences

Boxplots of the difference in percent cover between the two methods (diver - tow-camera), $\Delta$ cover $_{i}$, for each group of the A) benthic and B) coral community categories for each habitat ( $\mathrm{n}_{\text {slope }}=30$ paired, all other habitats $\mathrm{n}=18$ paired transects $)$. 

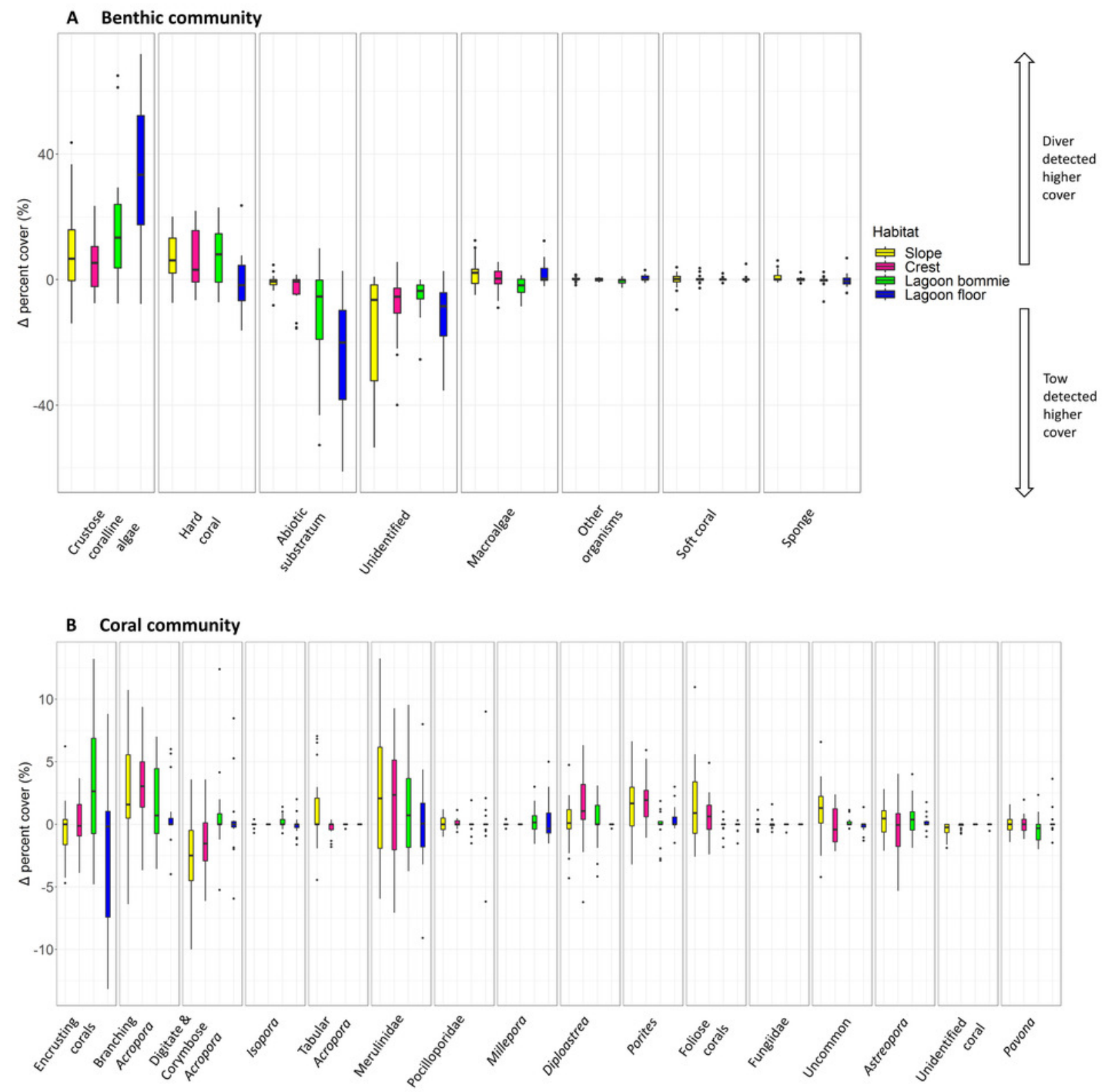